\title{
Attrition scrubbing for recovery of indium from waste liquid crystal display glass via selective comminution
}

\author{
Thomas Boundy, Marshall Boyton, Patrick Taylor \\ Department of Metallurgical and Materials Engineering, Kroll Institute for Extractive Metallurgy, Colorado School \\ of Mines, 1500 Illinois St., Golden, Colorado, USA \\ Corresponding author: Thomas Boundy \\ 1500 Illinois St. \\ Golden, CO 80401 \\ E: tiboundy@mines.edu
}

Word Count (excluding this line): 6975

\begin{abstract}
More than three quarters of global indium consumption is used for the manufacture of liquid crystal displays (LCDs). These devices contain indium at concentrations that appear to be too low to be economically valorized by standard hydro- or pyrometallurgical methods under current market conditions. Because indium is a metal critical to many electronics and clean energy technologies, developing commercially viable processes for recovery indium from such end of life products is expected to offer societal benefit. While LCD screens contain indium at low levels, the surface confinement of indium in these devices makes abrasion an intriguing option for concentrating indium to industrially relevant levels. To that end, attrition scrubbing is investigated and shown capable of producing a concentrate upgraded in indium concentration by a factor of 10 with greater than $90 \%$ recovery of indium. The same process leaves the LCD glass cleaned of semiconductor elements that are viewed as impurities to the glass recycling sector. Relative economics of such a pretreatment process relative to direct chemical processing routes are presented.
\end{abstract}

Key words: indium, recycling, attrition scrubbing, liquid crystal displays

\section{Introduction}

From 1985 to 2015 indium consumption grew by over 2000\% (Mines, 1985; Tolcin, 2016). Like many other technological metals for which production has grown rapidly over the last 30 years, recycling rates for indium from consumer goods are low - less than $1 \%$ (Graedel et al., 2011). The rapid expansion in demand and immature recycling network from post-consumer indium are of particular interest due to the importance of indium oxides, particularly indium tin oxide (ITO), as transparent conductive electrodes in solar photovoltaics which are expected to be manufactured in larger and larger volumes as societies lean more heavily on renewable energy sources. Additional increases in indium demand are expected due to the unique properties of indium that make it valuable to a low carbon economy in CIGS photovoltaic panels and LEDs particularly for fiber-optic communication (USGS, 2014).

In spite of the variety of growing uses for indium, it was estimated in 2010 that $74 \%$ of global indium consumption is used in flat panel displays as ITO (2010). A number of investigations citing similar trends look to LCDs as a source of secondary indium recovery. Rotter et al. have undertaken a thorough characterization of the material contents of the LCD screen including indium contents (Rotter et al., 2013). Most studies investigating routes to indium recovery utilize a hydrometallurgical approach. Li et al. report separation of screen components: removal of polarizer film by thermal shock, liquid crystals by ultrasonic cleaning, and indium by leaching in aqua regia (Li et al., 2009). Ruan et al. show improved leaching in sulfuric acid and improved purification through solvent extraction and the comparison of common extractants (Ruan et al., 2012). Hydrometallurgical recovery of indium from the dissolved trivalent indium species has been demonstrated via basic precipitation (Silveira et al., 2015) and zinc cementation (Rocchetti et al., 2016). While the hydrometallurgical approach is the commonly 
employed one for commercial recovery of low grade indium concentrates (Alfantazi and Moskalyk, 2003), some published approaches investigate pyrometallurgical routes to recovery. He et al. demonstrate the collection of volatile indium species from LCD screen glass residue through a carbothermal reduction at $1223 \mathrm{~K}$ at $1 \mathrm{~Pa}(\mathrm{He}$ et al., 2014). Takahashi et al. report an interesting avenue to indium recovery through hydrochloric acid mediated formation of indium chloride followed by selective vaporization at temperatures in the 400 to $700^{\circ} \mathrm{C}$ range (Takahashi et al., 2009). Much rarer are studies investigating novel mineral processing techniques. Dodbiba et al. note this trend as well, propose electrical disintegration as a pretreatment step to improve indium liberation prior to leaching, and report increased leaching yield and improved leaching kinetics as a result of the pretreatment (Dodbiba et al., 2012). To date, however, the low indium content has proven prohibitive to developing an economically viable recycling route.

Of course, commercial indium refiners already exist. Hydrometallurgical indium refiners typically process the lowest grade indium concentrates and under modern market conditions have a cut-off grade (lowest economical grade that can be processed) between 2000 and $3000 \mathrm{mg} / \mathrm{kg}$. Indium content is about $20 \mathrm{mg} / \mathrm{kg}$ in a typical computer monitor and about $200 \mathrm{mg} / \mathrm{kg}$ in the screen (Rotter et al., 2013; Ryan et al., 2011). The challenge to indium recovery from LCDs within existing recycling schemes is summarized in Fig. 1.

Commercial LCD Recycling Processes Commercial Indium Refining Processes

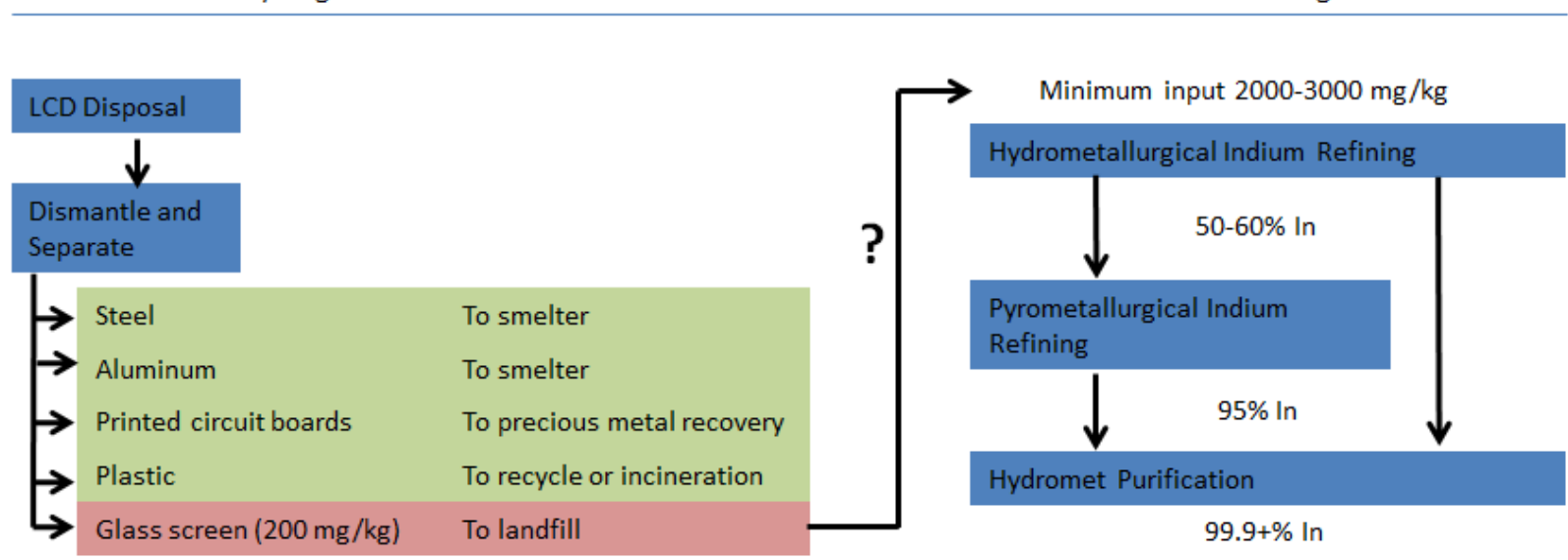

Fig. 1. Simplified description of modern commercial recycling processes for LCDs and indium concentrates illustrating the break in the loop that must be closed for commercial recovery of indium from LCDs.

Separation of the screen as shredder residue from the rest of the monitor has been demonstrated on the commercial scale through conventional mineral processing techniques. Other more sophisticated techniques have made important strides in automating the disassembly process and minimizing the risk associated with breakage of mercury containing fluorescent bulbs (O'Donoghue et al., 2014). Such innovations make the indium bearing screen easier to access, however, indium recovery from the screen by-product has proven elusive.

While refining costs pose a challenge to valorization of such dilute indium-containing materials, costs associated with transportation of such low-value material in moderate to low population density areas such as the United States further strain process economics. It has been suggested that abrasion-specific comminution would be an effective tool for upgrading indium content to a saleable level (Rotter et al., 2013); however, the authors are not aware of any high recovery mineral processing approaches to creating an indium concentrate from waste LCD screens that may more economically be processed via conventional hydrometallurgical techniques.

Attrition scrubbers have been used in mineral processing of certain ores for some time, but have found unique applicability in soil remediation operations to impart high shear on particle surfaces thereby liberating surface contaminants (Spiller, 1992). More recent published investigations have characterized some of the effects of important operating conditions (Bayley and Biggs, 2005; Ding et al., 2015; Kim et al., 2010). The mechanism of fracture in attrition scrubbing is illustrated in Fig. 2. 


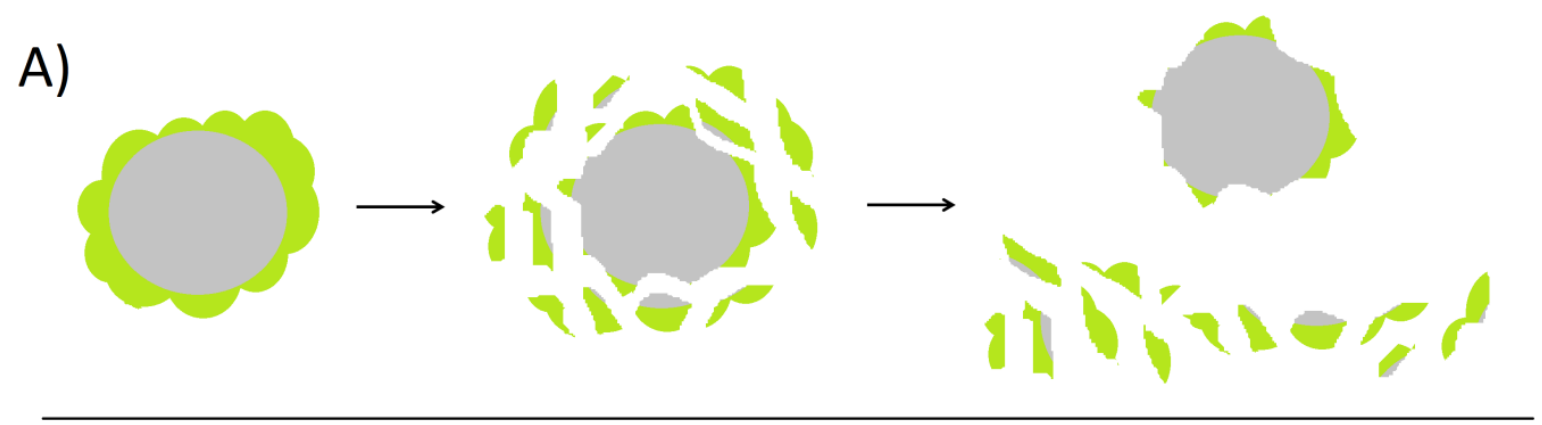

\section{B)}
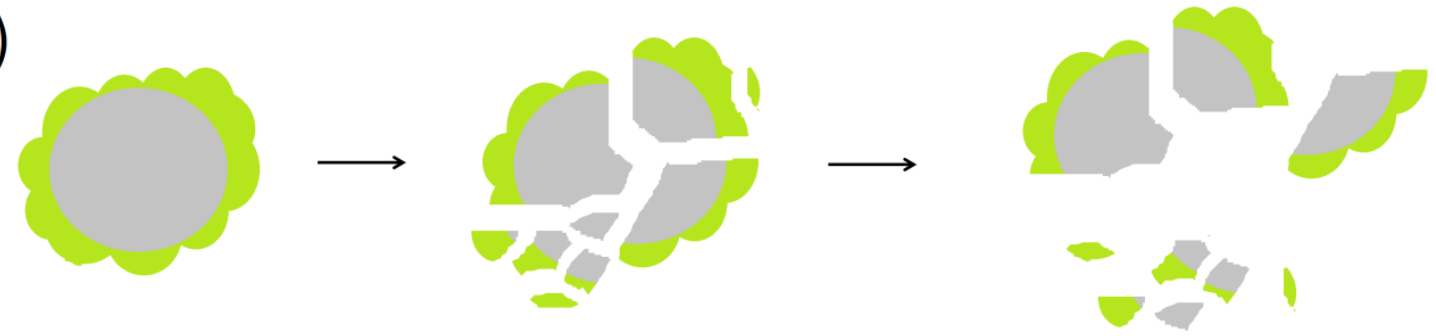

Fig. 2. Comparison of $A$ ) the abrasive action of the attrition scrubber and B) a typical non-selective grinding approach. Both A) and B) illustrate fracture of the particle followed by size classification. Adapted from Petavy (Petavy et al., 2009).

A separation of the contaminants from the soil can then be made based upon particle size. After screening or a similar size classification operation, the fines can either be landfilled or recycled for their metals content, and the cleaned coarse fraction can be returned for its original use.

Kim et al. recently published the first study known to the authors attempting to utilize attrition scrubbing for enrichment of values in a recycling operation; described is the use of scrubbing for platinum group metal (PGM) recovery from ceramic-honeycomb-type automobile catalytic converters (Kim et al., 2010). They report $81.2 \%$ recovery of PGMs from the crushed converter residue after 60 minutes of scrubbing in custom-made two-tiered attrition scrubber. Using a similar approach, Liu et al. achieved a comparable $78.9 \%$ recovery of PGMs, and suggest that due to the high value of PGMs and the fact that these values are currently able to be economically recovered from catalytic converters, losses of greater than 5\% of the total PGMs in an upgrading process are unacceptable (Liu et al., 2014). Liu et al. further note that $>80 \%$ recovery is very difficult to achieve due to concave surface of the crushed honeycomb structure limiting exposure of the PGM-rich coating to the surrounding abrasive slurry (Liu et al., 2014).

The two major challenges associated with PGM concentration from catalytic converters by attrition scrubbing are not applicable to LCD screens. The ITO coated glass has a flat geometry, and the concentration of indium in the screen is below that of cut-off grades for modern refining operation so indium is currently not recovered from these screens making losses in a concentrating operation less critical.

The slight concentration of indium in fine particle size fractions following conventional grinding techniques similar to those depicted in Fig. 2B has been noted (Rocchetti et al., 2015); however, to date, no tailored approach to abrasion specific comminution has been made. This work seeks to examine the use of attrition scrubbing as a means of concentrating indium from shredded LCD screens to levels suitable for commercial hydrometallurgical recovery.

\section{Methods and Materials}

\subsection{Characterization of LCD screen material}

Thirty monitors were collected and manually dismantled to recover the screens. Screens were shredded via industrial shredder with a tooth width of $1.75 \mathrm{~cm}$. Average indium concentration in the bulk sample of shredded 
screen was estimated by splitting, grinding in a ring and puck pulverizer (Angstrom TE250 Ring Pulversizer), pressing into pellets (Angstrom 4451 AE Briquet Press) with added boric acid as necessary, and subjecting four split samples to $x$-ray fluorescence (XRF) analysis (Thermo Scientific, PERFORM'X). Validation of indium content was performed by analyzing known ITO concentrations in a sand/polyethylene mixture (of an appropriate ratio to mimic the ratios found in the LCD screen) by XRF. External validation of those measurements was performed by fusing the glass samples with lithium borate, dissolving the mixture completely in nitric acid, and analyzing by inductively coupled plasma mass spectrometry (ICP-MS, Thermo Scientific, iCAP Qc) to confirm the general accuracy of the XRF measurements.

Shredder residue from the split fractions was separated by hand into front (darker) and back (lighter) glass sheets. Ten specimens of each were collected and subjected individually to Mohs hardness testing and nitric acid (10 $\mathrm{v} / \mathrm{v} \%$ ) leaching with leach liquor analysis by ICP-MS. Specimens were assigned Mohs hardness values equal to the average of the hardest standard mineral able to scratch it and the softest standard mineral unable to scratch the specimen. Leaching of screens with $10 \%$ nitric acid was performed across various time scales in order to determine the time at which complete leaching was achieved. Subsequent pieces of shredder residue were leached to completion, and the resulting liquors were subjected to ICP-MS for determination of indium concentration.

\subsection{Attrition scrubbing}

A Wemco laboratory flotation machine (71260-01) was modified for attrition scrubbing by fixing three propeller tiers with alternating handedness (right-left-right) to the rotating shaft within an octagonal agitation cell. LCD screen shredder residue was split into roughly $600 \mathrm{~g}$ samples for attrition scrubbing by a Jones riffle splitter. Tap water was added to the scrubber to create desired pulp densities, and samples were subjected to scrubbing at various agitation rates for various amounts of time. After the completion of scrubbing, samples were rinsed out of the scrubbing vessel across at 50 mesh (US) screen with at least four liters of water. The -50 mesh fraction was collected via pressure filter (Peterson Filters) across Whatman 5 filter paper and allowed to dry for 24 hours at ambient temperature. The collected filter cake was split via Jones riffle to prepare two samples for XRF analysis from which the average was reported. The investigated process is illustrated diagrammatically in Fig. 3.

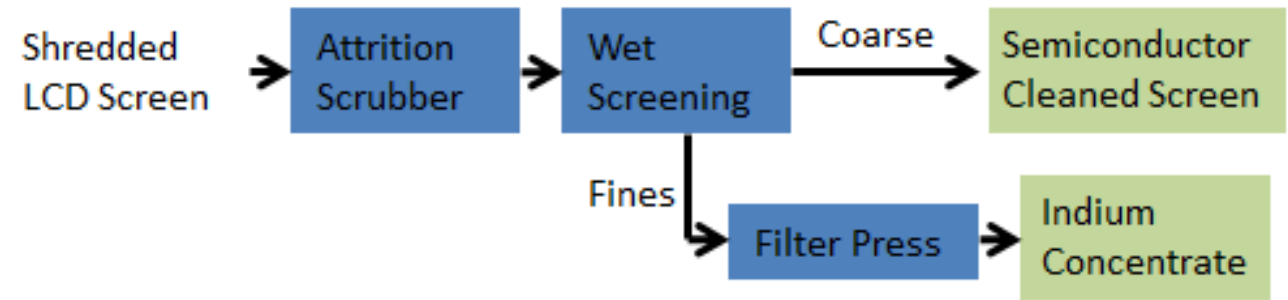

Fig. 3. Summary of proposed flow sheet investigated to fill missing link in Fig. 1.

In order to determine the effect of the selected screen size on grade and recovery values, the largest collected filter cake (52\% pulp density, 1100 RPM, 15 minutes) was separated into various size fractions by a ro-tap sieve shaker. The collected size fractions were weighed and leached for 24 hours in $10 \mathrm{v} / \mathrm{v} \%$ nitric acid. The leach liquors were analyzed for indium content by ICP-MS.

\section{Results and Discussion}

\subsection{LCD screen characterization}

As has been suggested by Rotter et al., general (or manufacturing) data, physical data, and chemical data are needed to guide selection of appropriate recycling strategies for critical materials (Rotter et al., 2013). These data are analogous to the understanding of the mineralogy of any primary ore dictating selection of comminution, beneficiation, and extraction processes.

Table 1

General data for the 30 monitors used in this study are shown in Table 1.

Characteristics of LCDs disassembled and shredded

\begin{tabular}{|l|l|l|}
\hline & Average & Standard Deviation \\
\hline Mass Device & $5.4 \mathrm{~kg}$ & $1.5 \mathrm{~kg}$ \\
\hline Screen Mass & $440 \mathrm{~g}$ & $71 \mathrm{~g}$ \\
\hline Screen Area & $1080 \mathrm{~cm}^{2}$ & $180 \mathrm{~cm}^{2}$ \\
\hline
\end{tabular}

The average indium concentration in the shredded screen material was determined to be $164 \mathrm{mg} / \mathrm{kg}$. Comparing this data to that found in the literature has become difficult. While there are a multitude of studies investigating the indium content of LCD screens, a number of studies lack sufficient detail for reproduction to be 
attempted. Further, it is not always clear whether a reported number represents the indium content in the plastic/glass/liquid crystal/glass/plastic sandwich (here referred to as the "screen"), or just the glass which has been separated from the plastic polarizer layers which account for approximately $15 \%$ of the screen's overall mass. A number of studies are shown for comparison in Table 2.

Table 2

Comparison of published average indium contents in waste LCD screen/glass. NS = not specified.

\begin{tabular}{llll}
\hline Method & Indium Content $(\mathrm{mg} / \mathrm{kg})$ & Mass Basis & Reference \\
\hline Leach/ICP-MS & 130 & Glass & (Rocchetti et al., 2015) \\
Leach/ICP-OES & 300 & Glass & (Ruan et al., 2012) \\
Leach/ICP-OES & 1000 & NS & (Dodbiba et al., 2012) \\
Leach/ICP-OES & $200 \pm 50$ & Screen & (Yang et al., 2013) \\
Leach/ICP-OES & $380-410$ & Glass & (Hasegawa et al., 2013) \\
Leach/AAS & $175 \pm 60$ & NS & (Rotter et al., 2013) \\
TCLP test & 102 & Glass & (Wang, 2009) \\
NS & 260.7 & NS & (Lee et al., 2013) \\
XRF & 164 & Screen & This Work \\
\hline
\end{tabular}

While the ICP techniques commonly employed are more powerful quantitative tools that an XRF, in the acid leach preparations employed, they require one to assume that all of the material of interest is effectively leached. If some of that material is contained within an unleachable matrix, even leaching with strong acid, high temperature, and to constant leached concentration may not be sufficient to dissolve this material. By comparison, it is noted that XRF is recognized as a semi-quantitative technique. In this case, verification of the original indium in glass content determination was performed by both an external standard analyzed by XRF ( $<5 \%$ error) and complete digestion of the glass followed by ICP-MS determination ( $<5 \%$ error). The $164 \mathrm{mg} / \mathrm{kg}$ indium content reported here is used in the context of this study merely to report a recovery value for the attrition scrubbing investigations.

In geologic ores, indium is mined as a by-product from zinc ores which contain indium at concentrations between 1 and $100 \mathrm{mg} / \mathrm{kg}$ (Tolcin, 2016). In these ores, zinc revenue covers nearly all of the cost of mining and extraction; indium revenue from these ores does not justify the entire cost of recovery. There are unique features of manufactured wastes, however, that can make valuable materials easier to recover relative to similar concentrations of those same materials in geologic sources. Loehr et al. note a number of unique features of manufactured wastes relative to primary ores that enable more efficient processing: more geometrically simple bonds between materials, more pronounced differences in material properties, and more consistent geometries, mechanical properties, and chemical contents of individual "particles" (Loehr and Melchiorre, 1996). As one looks to the structure of LCD screens with an interest in indium recovery (structure shown in Fig. 4.), one further notes the high degree of spatial confinement of the indium rich phase.
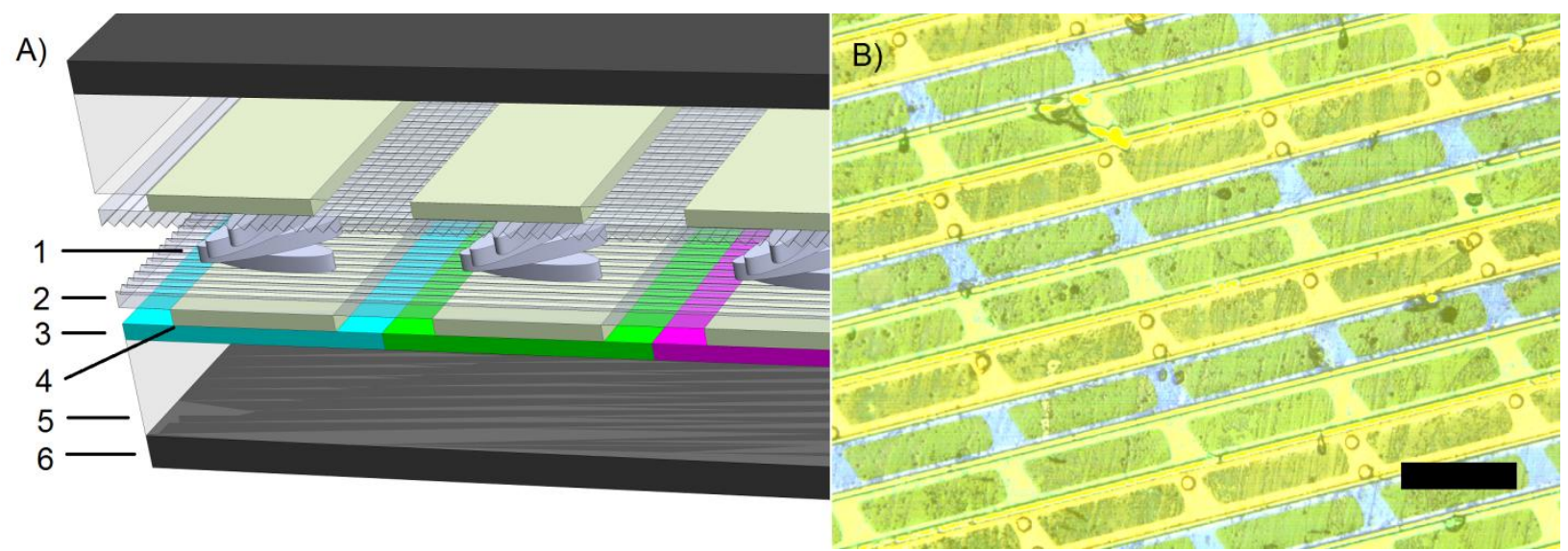

Fig. 4. A) A simplified diagram of the structure of a typical LCD screen. 1 - liquid crystals, $2=$ orientation layer, 3 $=$ color filter, 4 = ITO layer, $5=$ glass sheet, $6=$ polarizer. Not drawn to scale. Adapted from Kopacek, 2008. B) Micrograph of shredded LCD screen showing the individual pixels composed of three adjacent, independently controlled regions. Scale bar $=200$ microns. 
The spatial confinement of indium in the semi-conductor layer on the inward-facing surfaces of the glass sheets has caused some to propose abrasion as effective means of indium beneficiation (Rotter et al., 2013). Previous studies have noted a roughly two fold enrichment of indium in the fine particle size fraction following general shredding or milling operations (Rocchetti et al., 2015), but, to date, the authors do not believe an abrasion specific comminution approach has been successfully employed.

For such abrasion to be effective in an attrition scrubber; however, the glass of the screen must exhibit greater strength and hardness than does the semiconductor layers coating the glass.

The glass sheet without the color filter built in (henceforth "back glass") was observed not abrading as readily under the same conditions. Mohs hardness testing on front and back glass revealed a sizeable difference between the abrasion resistance of the different coatings. Front glass had an average Mohs hardness of 3.7 with a range of 2.5 to 4.5 ; the back glass on the other hand had an average hardness of 6.2 with a range of 5.5 to 6.5. When scratched with LCD screen glass, $100 \%$ of front glass coating tested could be abraded while only $90 \%$ of back glass coating could be abraded.

Leaching tests were performed in order to determine the theoretical maximum recovery of the scrubber based on the abrasion resistance of the back glass and the impact of slow abrasion kinetics. Leaching followed by ICP-MS analysis was selected instead of XRF analysis so that individual pieces of shredder residue could be analyzed and compared for indium content. A 24 hour leach was shown to give constant indium in the liquor when compared to 22 and 26 hours, so 24 hours was selected as the time interval for subsequent leaching studies. The front glass analyzed was found to contain an average of $245 \mathrm{mg} / \mathrm{kg}$ of indium ( $\mathrm{mg} \mathrm{In} / \mathrm{kg}$ screen) compared to 69 $\mathrm{mg} / \mathrm{kg}$ indium contained in the back glass. If it is assumed that $10 \%$ of the back glass is sufficiently abrasion resistant to make the contained indium unrecoverable, the theoretical maximum recovery drops to about $98 \%$. If it were assumed that only glass with a Mohs hardness less than 6 could be abraded (therefore assuming a typical 5.5 hardness for glass), the theoretical maximum recovery would drop to about $85 \%$.

\subsection{Attrition scrubber trend studies}

Through published investigations, the variables shown to have the greatest impact on abrasive action are residence time, agitation rate, temperature, and pulp density (Bayley and Biggs, 2005). The allocation of the chemical species is then ultimately determined by the subsequent size classification. The effect of the temperature of the slurry during scrubbing has only been shown to be effective for removal of organic species which is suspected to be due to decreased viscosity and adhesion and increased solubility of those species rather than an increased abrasive character (Bayley and Biggs, 2005). As such, temperature was not investigated for the removal of inorganic species in this study.

The LCD shredder residue is difficult to characterize in terms of particle size and morphology. Generally, the vast majority of particles are $2 \mathrm{~cm}$ wide strips of plastic polarizer with fractured glass adhered to one side. These strips vary in length from roughly 1 to $4 \mathrm{~cm}$. A picture of a general particle is shown in Fig. 8A. This type of particle comprises the vast majority of the mass. The remaining mass (approximately $10-15 \%$ of the total mass) is represented by glass fragments that have delaminated from the plastic polarizer backing.

The effect of pulp density on scrubbing efficiency was investigated by subjecting various pulp density slurries to 5 minutes of attrition scrubbing at $1100 \mathrm{rpm}$. The scrubber product was classified using a 48 mesh Tyler screen (50 mesh US) to produce an indium concentrate and tails. Trend curves for indium recovery, indium grade, and concentrate mass fraction are shown in Fig. 5. 


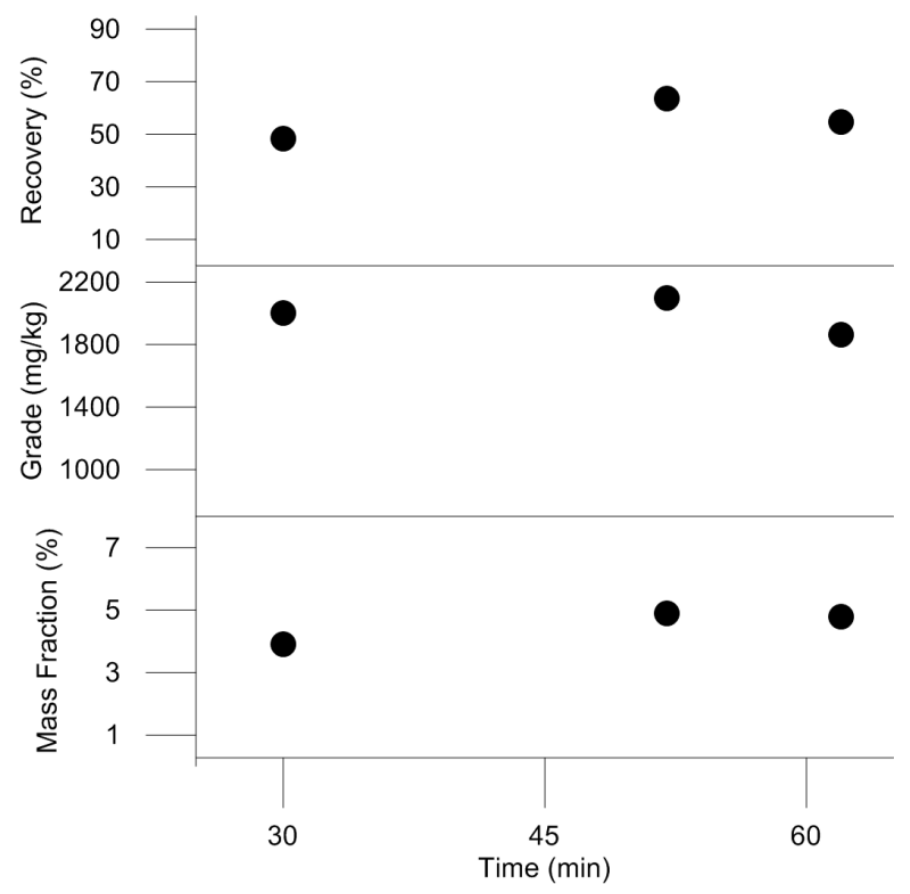

Fig. 5. Trends in fine scrubber product with varying pulp density.

Attrition scrubbers are commonly run in soil remediation processes at pulp densities around $70 \%$ solids by mass. With a typical soil this equates to approximately $47 \%$ solids on a volume basis. The LCD shredder product is a fairly coarse (shredder teeth were approximately $2 \mathrm{~cm}$ wide giving roughly the same width strips of screen) with a high aspect ratio. This causes them to pack poorly thereby limiting the maximum possible pulp density for pumping and scrubbing to approximately $52 \%$ solids by mass ( $34 \mathrm{vol} \%)$. Upon inspection of Fig. 5, one notes that the lower pulp densities produce a smaller proportion of fine product as would be expected due to decreased interparticle collisions in a lower solid content slurry. This phenomenon appears to level off as the slurry becomes waterdeficient above $52 \%$ solids. As the rate of fine indium-rich particles increases with increased pulp density, the maximum pulp density at which solids can be pumped in a slurry will be most desirable.

Agitation rate within the scrubber was varied while holding pulp density and scrubbing time constant at $52 \%$ and 5 minutes, respectively, and screening the product with a 50 mesh screen. The results are shown in Fig. 6. 


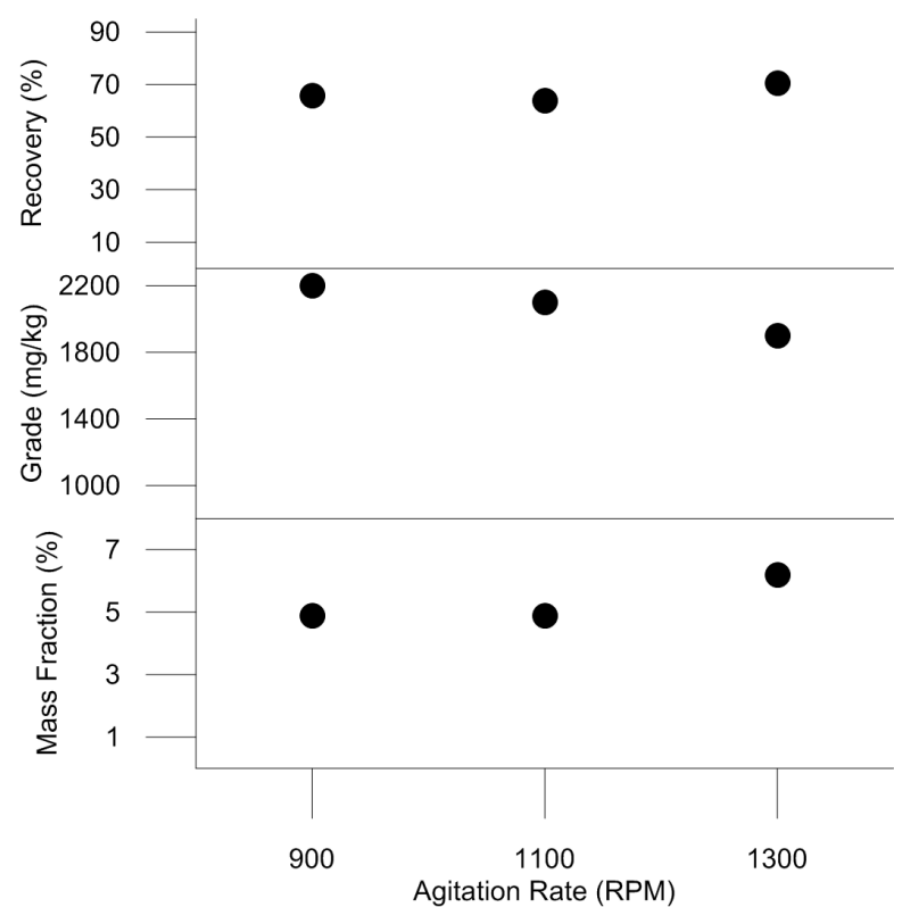

Fig. 6. Trends in fine scrubber product with varying agitation rate.

The range selected for study was that which induced high interparticle shear but did not produce excessive splashing of the slurry from the scrubbing vessel. Each of the trials was performed at $52 \%$ solids for 5 minutes of scrubbing. As can be observed from Fig. 6., increased scrubbing intensity correlates with more rapid generation of fine product, and a decrease in indium grade and increase indium recovery in that product. These trends are consistent with the expectation that more intense scrubbing would remove more surface material over a given time due to higher intensity impacts. As indium in the ITO layers is expected to be contained within only the surface 200 $\mathrm{nm}$ (Kopacek, 2010), one can very rapidly begin to dilute the product with indium-barren glass through abrasion of material deeper than the surface semiconductor layers.

The effect of scrubbing time was also investigated while holding pulp density and agitation rate constant at $52 \%$ and $1100 \mathrm{rpm}$, respectively, and screening with a 50 mesh screen. The results are shown in Fig. 7. 


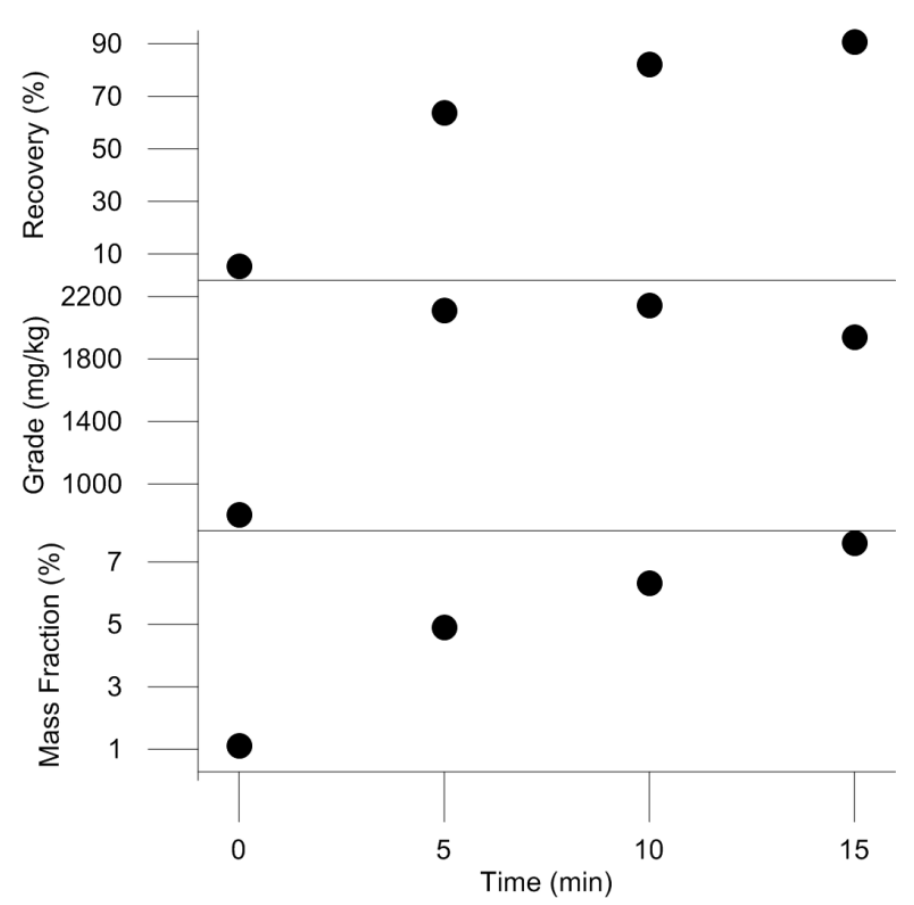

Fig. 7. Trends in fine scrubber product with varying agitation time.

The control for the scrubbing trials is represented as having undergone zero minutes of scrubbing; after just screening the -50 mesh particles from the scrubber product, the fine product represents just over one percent of the overall mass and contains about five percent of the indium at $800 \mathrm{mg} / \mathrm{kg}$.

The abrasion of the LCD screens over time most clearly provides understanding of the abrasion mechanism. Fig. 8 shows various pieces of front glass shredder residue after increasing exposure times to scrubbing. One can observe the scratches developing on the surface of the glass after 1 minute, and the nearly complete abrasion of the coating after 10 minutes.

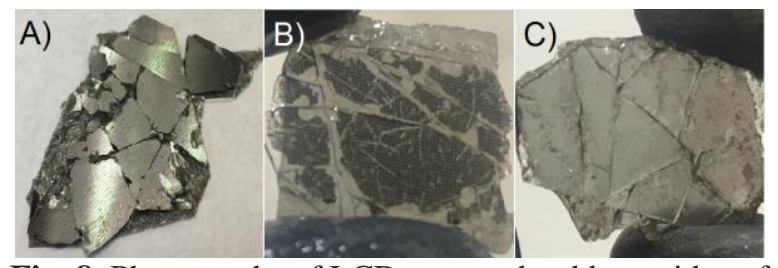

Fig. 8. Photographs of LCD screen shredder residue after A) 0 minutes, B) 1 minute, and C) 10 minutes of attrition scrubbing. The particle width in each case is approximately $2 \mathrm{~cm}$.

The increased scrubbing time predictably increases the mass of -50 mesh fines generated and overall fraction of indium contained in those fines. However, it is also noted, similar to increased agitation rate, after a certain point (here between 5 and 10 minutes), the slope of the grade curve flips from positive to negative indicating the time at which the average grade of each subsequent particle abraded from the glass has a lower indium concentration than the product previously generated. This trend of decreasing grade can be understood in light of the generation of scratches on the glass surface as shown in Fig. 8. As more scratches mar the surface, the likelihood that the next scratch will abrade a glass particle that contains no indium increases. Therefore, as more time is elapsed indium recovery is expected to increase and indium grade decreases. This trend is indeed observed after 5 minutes as shown in Fig. 7 and was discussed previously.

It was noted in accordance with coating scratch hardness values that the front abrades more readily than the back glass. It was apparent from similarly analyzed back glass that some particles withstood abrasion even after 15 minutes, and that they abraded more slowly on average than the front glass particles. 
The product produced by scrubbing a slurry of 52\% solids at $1100 \mathrm{rpm}$ for 15 minutes was subjected to a particle size analysis and chemical analysis to determine the indium fractionation and therefore the effect of the selected screen size on concentrate grade, recovery, and mass. The results of these analyses are shown in Fig. 9.

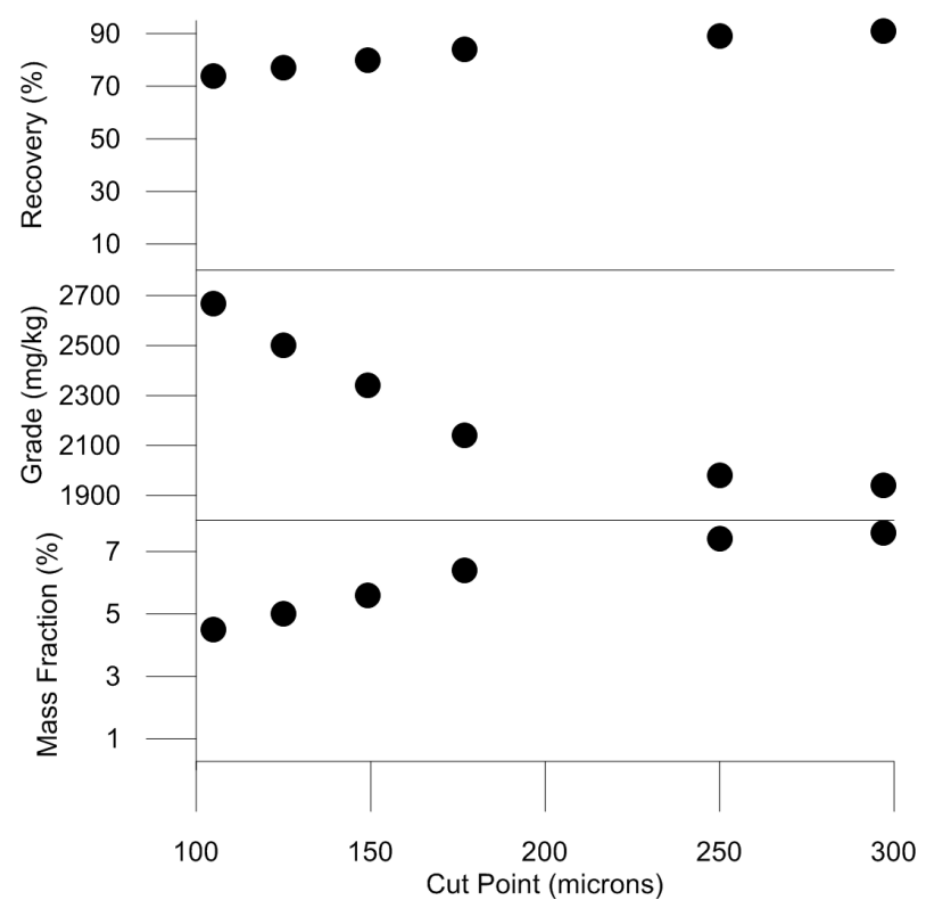

Fig. 9. Trends in fine scrubber product with varying screen size selection. Cut point refers to sieve opening size and therefore the largest size particle that can be contained in fine particle size fraction.

The implication of the trends observed from Fig. 9 is the increasing indium grade in finer particle size fractions. This is not surprising given the thin coating of ITO applied to the glass surface. For low aspect ratio particles generated by scrubbing, only a small portion of a particle that would be retained on an 80 mesh screen (opening 177 microns) could contain indium as ITO. A perfectly cubic particle with 177 micron edge length with one face containing $100 \mathrm{~nm}$ deep ITO and the rest composed of glass (specific gravity $=2.65$ ) would contain roughly $1300 \mathrm{mg} / \mathrm{kg}$ indium. This is approximately twice the grade of the fraction retained on this screen in the analysis shown above $(700 \mathrm{mg} / \mathrm{kg})$. Of course, the theoretical number will not reflect reality due to the simplicity of the geometry involved and the dilution by non-indium-containing particles; however, the example does serve to illustrate a general limit to the indium content based on particle size and the thickness of the indium coating on the original glass sheet.

This particle size dependent phenomenon provides an additional layer of control over the scrubbing process. The effects of screen size and scrubbing most clearly illustrate the trade-off between product grade and recovery. The increasing grade of indium in the concentrate is indicative of the enrichment of indium in low particle size fractions. As increasingly fine screen sizes are used, a greater mass of low grade indium is rejected leading to a higher grade indium product with decreased overall indium recovery.

\subsection{Cost Considerations}

Two brief comparisons were made to justify the use of the attrition scrubber as a beneficiation step prior to hydro- or pyrometallurgical processing. A simple model of indium value recovered and selected operating costs for a direct leach of waste LCD screen material with a leach of pretreated scrubber material was created to illustrate the advantages of the pretreatment step. A second model was prepared in similar fashion comparing a pyrometallurgical recovery process using either waste LCD screen or the scrubber product as generated here. General assumptions for both models are listed in Table 3.

Table 3. Values for parameters used in the calculation of models shown in Tables 4 and 5. 


\begin{tabular}{lc} 
Assumed Parameters & \\
\hline Indium Content in Feed (mg/kg) & 200 \\
Indium Price (USD/kg) & 500 \\
Mass Ratio Scrubber Concentrate & 0.08 \\
Electricity Cost (USD/MJ) & 0.0556 \\
Natural Gas Cost (USD/MJ) & 0.0222 \\
Water and Treatment Cost (USD/metric tonne water) & 1.77 \\
Leaching Solid Liquid Ratio (kg feed/kg acid) & 1 \\
Sulfuric acid concentration (M) & 2 \\
Sulfuric acid cost (USD/tonne) & 100 \\
Precipitation $\mathrm{pH}$ & 3 \\
NaOH Cost (USD/tonne) & 600 \\
Glass Heat Capacity $\left(\mathrm{J} / \mathrm{g}{ }^{\circ} \mathrm{C}\right)$ & 0.84 \\
Furnace Heat Efficiency & 0.5
\end{tabular}

For the hydrometallurgical comparison, a leach and cement process was chosen such as has been described previously in the literature (Rocchetti et al., 2016). This process was selected as it requires the smallest $\mathrm{pH}$ adjustment (only an increase to a $\mathrm{pH}$ of 3 for effective cementation) and the costs of acids and bases are the highlight of this comparison. A mass basis of 1000 tonnes of shredded LCD screen was chosen. The scrubber circuit modeled here comprises a 12 horsepower scrubber assumed to operate at full power, half capacity, with a 30 minute particle residence time, and 52\% solids in the slurry, a 5 horsepower vibratory screen operating at full power, and a 5 horsepower filter press operating at full power. Expected water treatment costs and maintenance costs were estimated using CostMine 2016 database (Estimating, 2016). The recovery of indium in the leach and precipitation step was assumed to be $95 \%$ while the recovery in the attrition scrubbing circuit was assumed to be $90 \%$. The products of both processes were assumed to be of the same value, and the same quantity of zinc was assumed for cementation.

Table 4. Economic comparison of selected operating costs and revenues associated with a leach circuit and an attrition scrubber pretreated leach circuit.

\begin{tabular}{lcc} 
& Scrub/Leach & Leach \\
\cline { 2 - 3 } Feed (metric tonnes) & 1000 & 1000 \\
Recovery & 0.855 & 0.95 \\
Total Indium Value (USD) & 85500 & 95000 \\
\hline Scrubber Circuit Energy Cost (USD) & 287 \\
Scrubber Circuit Water Treatment Cost (USD) & 1634 & \\
Scrubber Maintenance Costs (USD) & 654 & \\
Acid Cost (USD) & 2944 & 18400 \\
Base Cost (USD) & 4288 & 53600 \\
\hline Net Value (USD) & 76347 & 23000
\end{tabular}

Table 4 illustrates the amount of acid and neutralizing base consumed is significantly decreased in the system with scrubber pretreatment. The cost of added reagents along justifies the costs and indium losses associated with scrubbing in this example. The economic advantages in a more complete model would also have to take into account the approximately 12 -fold increase in the leaching plant size, the increased costs associated with pumping 12 times the fluid, and the increased losses associated with cementing indium from a more dilute solution.

A similar comparison is presented in Table 5 comparing the costs of heating the material for a pyrometallurgical recovery of indium using a scrubber product feed and an untreated LCD screen feed. The model is based on a process presented previously in the literature (Takahashi et al., 2009), as it will be the most favorable from a cost perspective for this analysis given the low operating temperature. However, the indium chlorination reaction is assumed here to occur via a gas phase reaction instead of via hydrochloric acid digestion to avoid the same acid consumption cost comparison illustrated in the previous example. A natural gas heated furnace operating 
at $500^{\circ} \mathrm{C}$ fed with oxygen enriched air to $50 \%$ oxygen with was assumed. Complete combustion under perfect stoichiometric conditions was assumed. At operating temperature, the furnace was assumed to lose $50 \%$ of the input heat to the surroundings. Natural gas was assumed to be $100 \%$ methane. The mass of the plastic in the screen (assumed 15\%) was subtracted from the mass to be heated, and the heat content of the plastic was not included in the heat balance equations as the same mass could be added to the furnace or sold for value in either case. The recovery of indium in the selective volatilization furnace was assumed to be $90 \%$.

Table 5. Economic comparison of selected operating costs and revenues associated with a selective vaporization of indium chloride with and without an attrition scrubbing pretreatment.

\begin{tabular}{lcc} 
& Scrub/Pyro & Pyro \\
\cline { 2 - 3 } Feed (metric tonnes) & 1000 & 1000 \\
Recovery & 0.81 & 0.9 \\
Total Indium Value (USD) & 81000 & 90000 \\
\hline Scrubber Circuit Energy Cost (USD) & 287 & \\
Scrubber Circuit Water Treatment Cost (USD) & 1634 & \\
Scrubber Maintenance Costs (USD) & 654 & 16608 \\
Natural Gas Cost (USD) & 1563 & 73392
\end{tabular}

Again, one notes the added costs of processing without the preprocessing step outweigh the losses due to imperfect recovery and the added costs of the scrubber treatment under conditions favorable to the route without pretreatment. Additional costs not compared here are those associated with the much larger furnace size, increased volumes of off-gas, and materials handling equipment (loaders, conveyors, etc.). The magnitude of such costs is expected to be exacerbated by the materials of construction limitations imposed by the chloride environment required for low temperature vaporization of indium.

It should be noted that these results in no way suggest the overall economic viability of any overall process. Instead, the results merely suggest that if indium is to be recovered from waste LCD screens, the preprocessing step described in the present work are expected to have economic advantages relative to direct chemical processing routes.

\subsection{Scrubbing impact on LCD glass}

As with indium recovery from geologic ores, the economic justification for indium recovery from waste LCD screens is improved as more different components of the material are valorized. A number of published studies suggest the glass could be sold as an additional revenue stream; however, the proposed applications are limited to low value uses such as pozzolanic material or feed for sintered ceramics (Lin et al., 2009a; Lin et al., 2009b; Wang, 2009). These approaches are effective low-value uses of the LCD glass. The suitability of waste LCD glass for higher value glass applications may be limited by the content of elements used in the semiconductor layers of the glass. Removal of some of these materials from the glass would likely constitute an improvement in the marketability of LCD glass for higher value applications for which elements like copper, indium, cerium, and titanium are undesirable. As a result, the coarse product generated by the scrubbing process may constitute a more valuable glass product than the feed material that contains ITO and other semiconductor layers. Qualitative observation of the glass cleaning of semiconductor layers on the glass surface can be seen by comparison of Fig. 6A and $6 \mathrm{C}$. Table 6 provides a more quantitative illustration of the cleaning process through presentation of the mass balance for various elements contained within the screen in the original feed material and the fine and coarse products generated from the attrition scrubbing process.

Table 6. Chemical composition of scrubber feed material and coarse ( +50 mesh) and fine $(-50$ mesh) particle size fractions. Values for feed and fine columns represent measured values, and the coarse values are calculated from the mass balance.

\begin{tabular}{|l|l|l|l|}
\hline & Feed (\%) & Fine (\%) & Coarse (\%) \\
\hline $\mathrm{SiO}_{2}$ & 56.48 & 52.78 & 56.78 \\
\hline $\mathrm{Al}_{2} \mathrm{O}_{3}$ & 16.71 & 15.47 & 16.81 \\
\hline
\end{tabular}




\begin{tabular}{|l|l|l|l|}
\hline $\mathrm{MgO}$ & 0.774 & 0.732 & 0.777 \\
\hline $\mathrm{CaO}$ & 6.18 & 6.43 & 6.16 \\
\hline $\mathrm{SrO}$ & 2.1 & 2.01 & 2.11 \\
\hline $\mathrm{BaO}$ & 3.49 & 2.42 & 3.58 \\
\hline $\mathrm{Na}_{2} \mathrm{O}$ & 0.151 & 0.138 & 0.152 \\
\hline $\mathrm{As}_{2} \mathrm{O}_{3}$ & 0.622 & 0.665 & 0.618 \\
\hline $\mathrm{Fe}$ & 0.107 & 0.642 & $\mathrm{SS}$ \\
\hline $\mathrm{Ni}$ & 0.001 & 0.051 & $\mathrm{SS}$ \\
\hline $\mathrm{Cr}$ & 0.0123 & 0.171 & $\mathrm{SS}$ \\
\hline $\mathrm{Cu}$ & 0.0088 & 0.0431 & $\mathrm{ND}$ \\
\hline $\mathrm{SnO}_{2}$ & 0.118 & 0.164 & 0.114 \\
\hline $\mathrm{In}_{2} \mathrm{O}_{3}$ & 0.0159 & 0.2306 & $\mathrm{ND}$ \\
\hline $\mathrm{CeO}_{2}$ & $\mathrm{ND}$ & 0.094 & $\mathrm{ND}$ \\
\hline $\mathrm{TiO}_{2}$ & 0.0055 & 0.195 & ND \\
\hline
\end{tabular}

$\mathrm{ND}=$ not detected, detection limit $=10 \mathrm{mg} / \mathrm{kg}$

$\mathrm{SS}=$ not calculated due to stainless steel contamination

As expected, components of the bulk glass are slightly depleted in the fine indium concentrate. Among the elements enriched in the fine product are iron, nickel, and chromium; these elements increase in the fine product in proportions roughly equivalent to their alloying ratios in 304 stainless steel which composes the scrubbing blades. The slow abrasion of the scrubber blades is to be expected due to the highly abrasive character of the glass and is not expected to limit the viability of the operation. Other elements enriched in the fine product include copper, indium, tin, cerium, and titanium. The removal of copper (used in surface electrical circuitry), indium (as ITO), cerium (as $\mathrm{CeO}_{2}$ used in glass polishing), and titanium (as $\mathrm{TiO}_{2}$ used as an adhesion promoter) from the coarse product below $10 \mathrm{mg} / \mathrm{kg}$ improves the utility of the coarse for glass manufacturers seeking a secondary source of glass. While tin is included as a component of ITO and is therefore enriched in the fine product, it is also a component of the bulk glass either as an intentional additive or contaminant from electrodes or a tin float bath. For this reason, it is not surprising that tin concentration is only modestly reduced from the feed material in the coarse product.

After scrubbing much of the cleaned glass product remains adhered to the plastic polarizer backing. Admittedly, before admission into a conventional glass recycling stream, a plastic/glass separation similar to those found elsewhere in the LCD literature (Li et al., 2009) or in the automotive windshield recycling industry (Tupy et al., 2014).

\section{Conclusion}

Direct recovery of indium from LCD screens via hydro and pyrometallurgical techniques is a costly proposition due to the low indium contents of the material. The surface confinement of indium on LCD screen glass enables the beneficiation of indium via attrition scrubbing. Attrition scrubbing of LCD screen shredder residues is a low-cost process over which a high degree of control can be imposed ultimately leading to the production of a higher concentration indium product which may be economically processed by current industrial refining methods. Through the abrasion of elements contained in the semiconductor layers of LCD glass, the abraded glass residue may be more readily recycled into glass products which require decreased contaminant loads. These features of the attrition scrubbing process are thought to provide significant commercial advantages relative to methods for direct recovery of indium from the bulk screen described previously in the literature.

\section{Notes}

Declaration: T.B and P.T. filed a provisional patent application (US application number, 62/329076; filing date 28 April 2016) concerning the process detailed in the present investigation.

Acknowledgements 
The authors gratefully acknowledge Erik Spiller for helpful discussions surrounding attrition scrubbing applications, and Resource Development Inc. for the use of their attrition scrubber for initial suitability studies. Larry Stevens and Indium Corporation also provided meaningful insight into indium refining practices and acceptable feed materials for such processes.

Funding: This research is supported by the Critical Materials Institute, an Energy Innovation Hub funded by the U.S. Department of Energy, Office of Energy Efficiency and Renewable Energy, Advanced Manufacturing Office.

\section{References}

European Commission, Enterprise and Industry (2010) Annex V to the Report of the Ad-hoc Working Group on defining critical raw materials. European Commission, Enterprise and Industry, Brussels, Belgium, pp. 91-96.

Alfantazi A, Moskalyk R (2003) Processing of indium: a review. Minerals Engineering 16:687-694.

Bayley R, Biggs C (2005) Characterisation of an attrition scrubber for the removal of high molecular weight contaminants in sand. Chemical Engineering Journal 111:71-79.

Ding Y, Chih-Chien L, Cheng T (2015) The Purification of Crude Zinc Oxide Using Scrubbing, Magnetic Separation, and Leaching Processes. Separation Science and Technology 50:2405-2414.

Dodbiba G, Nagai H, Wang LP, Okaya K, Fujita T (2012) Leaching of indium from obsolete liquid crystal displays: Comparing grinding with electrical disintegration in context of LCA. Waste Management 32:1937-1944.

Estimating CMC (2016) Mining Cost Service. Jennifer B. Leinart, Spokane, WA.

Graedel TE, Allwood J, Birat J-P, Buchert M, Hagelueken C, Reck BK, Sibley SF, Sonnemann G (2011) What Do We Know About Metal Recycling Rates? Journal of Industrial Ecology 15:355-366.

Hasegawa H, Rahman IMM, Egawa Y, Sawai H, Begum ZA, Maki T, Mizutani S (2013) Recovery of indium from end-of-life liquid-crystal display panels using aminopolycarboxylate chelants with the aid of mechanochemical treatment. Microchemical Journal 106:289-294.

He Y, Ma E, Xu Z (2014) Recycling indium from waste liquid crystal display panel by vacuum carbonreduction. Journal of Hazardous Materials 268:185-190.

Kim W, Kim B, Choi D, Oki T, Kim S (2010) Selective recovery of catalyst layer from supporting matrix of ceramic-honeycomb-type automobile catalyst. Journal of Hazardous Materials 183:29-34.

Kopacek B ReLCD Recycling and Re-Use of LCD Panels. in leee International Symposium on Sustainable Systems and Technology (Issst), Durban, South Africa.

Lee $\mathrm{C}-\mathrm{H}$, Jeong M-K, Kilicaslan MF, Lee J-H, Hong H-S, Hong S-J (2013) Recovery of indium from used LCD panel by a time efficient and environmentally sound method assisted HEBM. Waste Management 33:730-734.

Li J, Gao S, Duan H, Liu L (2009) Recovery of valuable materials from waste liquid crystal display panel. Waste Management 29:2033-2039.

Lin K-L, Chang W-K, Chang T-C, Lee C-H, Lin C-H (2009a) Recycling thin film transistor liquid crystal display (TFT-LCD) waste glass produced as glass-ceramics. Journal of Cleaner Production 17:1499-1503.

Lin KL, Huang W-J, Shie JL, Lee TC, Wang KS, Lee CH (2009b) The utilization of thin film transistor liquid crystal display waste glass as a pozzolanic material. Journal of Hazardous Materials 163:916-921.

Liu G, Ichinose T, Tokumaru A, Owada S (2014) Surface-Grinding Kinetics for the Concentration of PGMs from Spent Automobile Catalysts by Attritor Surface Grinding. Materials Transactions 55:978-985.

Loehr K, Melchiorre M (1996) Liberation of composite waste from manufactured products. International Journal of Mineral Processing 44-5:143-153.

Mines Bo (1985) Minerals yearbook metals and minerals. pp. 1092-1093. 
O’Donoghue L, Leen J, Ryan A, Ruiz J (2014) State-of-the-Art Recycling Technology for LiquidCrystal Displays. Environmental Protection Agency, Ireland.

Petavy F, Ruban V, Conil P, Viau J, Auriol J (2009) Treatment and Valorisation of Stormwater Sediments. Global Nest Journal 11:189-195.

Rocchetti L, Amato A, Beolchini F (2016) Recovery of indium from liquid crystal displays. Journal of Cleaner Production 116:299-305.

Rocchetti L, Amato A, Fonti V, Ubaldini S, De Michelis I, Kopacek B, Veglio F, Beolchini F (2015) Crosscurrent leaching of indium from end-of-life LCD panels. Waste Management 42:180-187.

Rotter V, Chancerel P, Ueberschaar M (2013) Recycling-Oriented Product Characterization for Electric and Electronic Equipment as a Tool to Enable Recycling of Critical Metals. REWAS 2013 Enabling Materials Resource Sustainability 2013:192-201.

Ruan J, Guo Y, Qiao Q, Jinhui L, Hualong H (2012) Recovery of indium from scrap TFT-LCDs by solvent extraction. Seventh International Conference on Waste Management and Technology (Icwmt 7) 16:545551.

Ryan A, O' Donoghue L, Lewis H (2011) Characterising components of liquid crystal displays to facilitate disassembly. Journal of Cleaner Production 19:1066-1071.

Silveira A, Fuchs M, Pinheiro D, Tanabe E, Bertuol D (2015) Recovery of indium from LCD screens of discarded cell phones. Waste Management 45:334-342.

Spiller DE (1992) Environmental Applications of Mineral Processing Technologies. Minerals Engineering 5:1433-1437.

Takahashi K, Sasaki A, Dodbiba G, Sadaki J, Sato N, Fujita T (2009) Recovering Indium from the Liquid Crystal Display of Discarded Cellular Phones by Means of Chloride-Induced Vaporization at Relatively Low Temperature. Metallurgical and Materials Transactions a-Physical Metallurgy and Materials Science 40A:891-900.

Tolcin A (2016) Mineral Commodity Summaries: Indium. USGS, Reston, Virginia.

Tupy M, Mokrejs P, Merinska D, Svoboda P, Zvonicek J (2014) Windshield Recycling Focused on Effective Separation of PVB Sheet. Journal of Applied Polymer Science 131.

Wang $H$ (2009) A study of the effects of LCD glass sand on the properties of concrete. Waste Management 29:335-341.

Yang J, Retegan T, Ekberg C (2013) Indium recovery from discarded LCD panel glass by solvent extraction. Hydrometallurgy 137:68-77. 


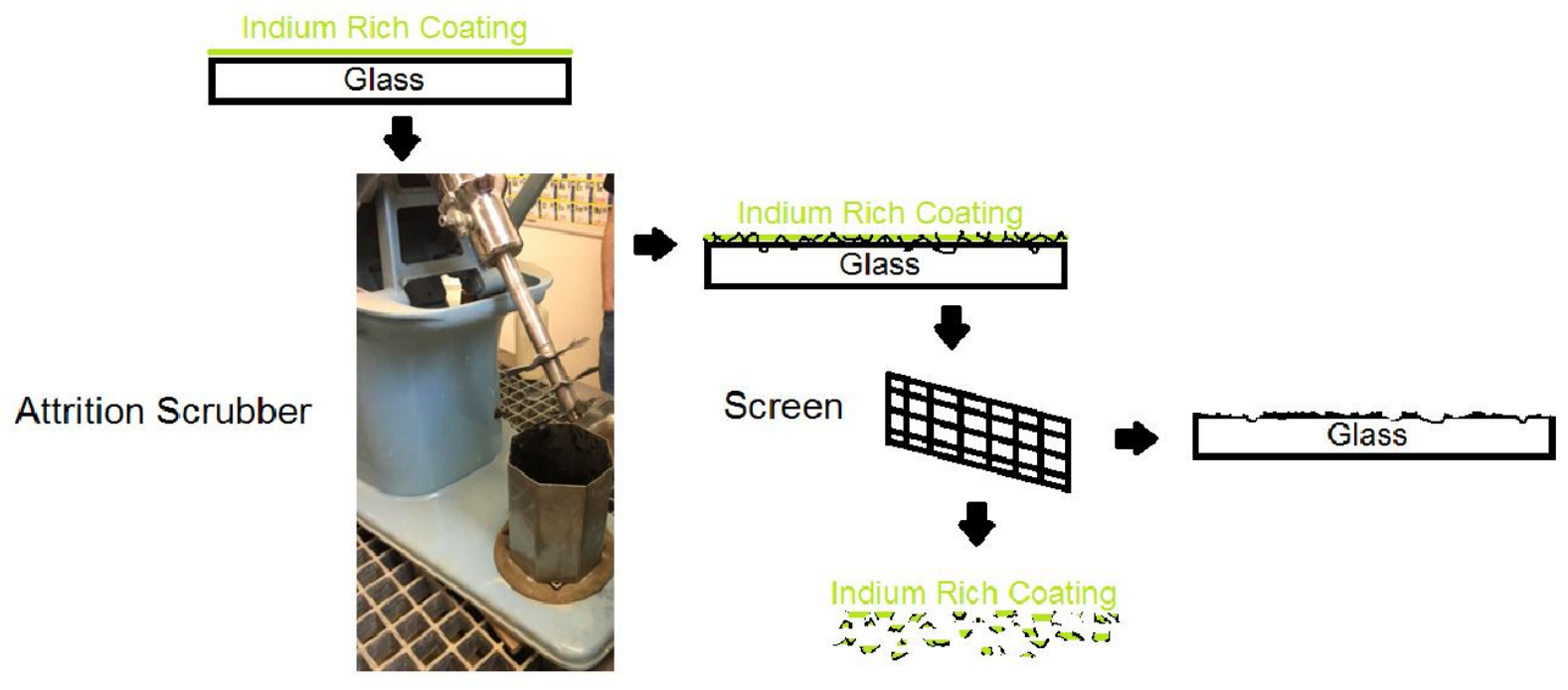

